\title{
Corporate Responsibility and Corporate Reputation: Two Separate Concepts or Two Sides of the Same Coin?
}

\author{
Carola Hillenbrand \\ The John Madejski Centre for Reputation, School of Reputation and \\ Relationships, Henley Management College, Greenlands, \\ Henley-on-Thames, Oxon, UK
}

\author{
Kevin Money \\ The John Madejski Centre for Reputation, School of Reputation and \\ Relationships, Henley Management College, Greenlands, \\ Henley-on-Thames, Oxon, UK
}

\begin{abstract}
The need to investigate the link between reputation and responsibility is well established. This paper answers calls to conduct this comparison from a stakeholder perspective. In so doing a literature review identified models of reputation that engage with stakeholders from their inception to measurement, while no such models of corporate responsibility were found. A qualitative study to conceptualize responsibility from the perspective of stakeholders was then conducted. Following this, a formal comparison between this conceptualization and that of reputation models is undertaken. The results suggest that there is considerable similarity between the concepts of responsibility and reputation. Implications may include the use of reputation models as potential measures for many of the aspects conceptualized as responsibility. Questions about the causal relationship between the two concepts are also discussed.

Corporate Reputation Review (2007) 10, 261-277. doi:10.1057/palgrave.crr.1550057
\end{abstract}

KEYWORDS: corporate reputation; corporate responsibility; stakeholders

\section{INTRODUCTION}

In recent years, practitioners and academics have become increasingly interested in reputation and how it relates to other concepts such as responsibility (eg Brammer and Pavelin, 2006; Fombrun, 2005; Andriof and Waddock, 2002). In part, this is because elements of responsibility have been viewed as key drivers of reputation. Antecedents of a good reputation have been suggested to include embracing CSR standards (Fombrun, 2005), philanthropic giving (Brammer and Millington, 2005) and the development of trusting relationships with stakeholders (MacMillan et al., 2004; Waddock, 2002; Jones, 1995).

On the other hand, some theorists suggest that rather than being an antecedent of reputation, issues relating to the responsibilities of a business are key attributes in terms of which an organization's reputation is judged. Schnietz and Epstein (2005), for example, identify social responsibility as a key dimension of reputation; Tucker and Melewar (2005) see social responsibility as a critical element of reputation relevant to crisis management and Lindgreen and Swaen (2005)
Corporate Reputation Review, Vol. 10, No. 4, pp. 261-277 (C) 2007 Palgrave Macmillan Ltd, 1363-3589 $\$ 30.00$ 
argue that issues relating to responsibility are embedded within the functional relationships that underpin business activities. They suggest, therefore, that there will be a significant overlap between the reputation for these activities and the reputation for issues relating to responsibility.

It is thus not clear from the current literature how responsibility and reputation interact. Does responsibility lead to a good reputation? Or is reputation judged in terms of issues relating to responsibility and other characteristics? The key difference between these two approaches is the following: The first approach sees responsibility as preceding reputation, or in other words as bringing about a good or bad reputation. The second approach sees responsibility as an inherent part of reputation, in other words as a key element in terms of which reputation is described. At this stage both, one or neither of these propositions might be true. This paper, therefore, sets out to compare these two concepts. To achieve this, the paper follows five related steps:

1. First, literature relating to reputation is reviewed.

2. Second, literature relating to responsibility and its related constructs such as CSR is reviewed.

3. Third, stakeholder literature is reviewed with the aim of developing an approach to bring together literature on reputation and responsibility.

4. Fourth, the findings of a qualitative research study are presented.

5. Finally, the conceptualizations of responsibility and reputation are compared and contrasted with a view to reaching a better understanding how these concepts interact.

\section{CORPORATE REPUTATION}

Corporate Reputation is a multi-stakeholder concept that is reflected in the perceptions that stakeholders have of an organization
(Smidts et al., 2001). There is much evidence that reputations with different stakeholder groups interact. In particular, reputation with employees is seen to have an impact on reputation with customers and communities (Carmeli, 2005). When managing their Corporate Reputation, organizations should therefore take account of not only their relationships with stakeholders but also monitor how stakeholders influence each other (Dutton et al., 1994).

A review of existing models of Corporate Reputation reveals a relatively small number of widely used models, the most prominent of which seem to be variations of Fortune's Most Admired Companies List (MAC) and the Reputation Quotient (RQ) (Fombrun and Van Riel, 2004; Fombrun, 1996). Also popular but to a lesser extent are models such as the Corporate Personality Scale (Davies et al., 2003) and the Stakeholder Performance Indicator and Relationship Improvement Tool (SPIRIT) (MacMillan et al., 2004). These models differ considerably in terms of their underlying approach, the stakeholder they survey and what they measure (Mahon, 2002).

For example, the MAC List surveys CEOs and financial analysts about their view of listed companies in terms of issues such as innovation, financial soundness, use of corporate assets and social responsibility. The list was developed by the Fortune's editorial panel in discussion with business leaders and financial analysts and sought to identify characteristics that executives and financial experts admire in companies. Subsequent analysis of the data revealed that all components factored on one underlying dimension, which can best be described as a financial dimension (Fryxell and Wang, 1994).

The RQ, on the other hand, can be applied to obtain data on a company's reputation from the point of view of the general public, customers, employees, suppliers and investors. Although, in practice, surveys with the general public and customers have been 
influences such as experience of what the media has to say about a business or how a business treats other stakeholder groups. Feelings refer to the level of trust and positive emotions that stakeholders feel towards a business. Intentions of stakeholders measure the likelihood that stakeholders will support the business in the future, for example through stakeholder retention, advocacy and cooperation. The scale was developed through a literature review of reputation, marketing and psychology literature and followed by focus groups and interviews. The concepts in the model were modified and refined and questionnaires were developed to measure aspects in the model. These were distributed to 8,000 stakeholders of different kinds across three different continents. Statistical Techniques, such as factor analysis and structural equation modeling, confirmed the independence of the measures and the proposed links between reputation, its causes and consequences.

These models are now summarized in Table 1 with reference to their main features.

As described in Table 1, models differ from each other according to their underlying approach, the stakeholders they survey and what they measure. The way a model is developed and the underlying assumptions of theorists have an impact on when it is most appropriate to use different models. For example, it is important to consider when it is appropriate to use a personality metaphor or a relationship metaphor and to consider what useful data could be obtained from different stakeholder groups. We have already stated we will take a stakeholder perspective and this means focussing on models that ely upon stakeholder expectations in their underlying approach. Since the RQ and SPIRIT models are developed with stakeholder perceptions and expectations as their fundamental starting points, these two models will be used as a basis for the comparison with a conceptualization of responsibility developed from a similar provides to stakeholders and outside 
Table 1: Summary of Reputation Models

\begin{tabular}{l}
$\begin{array}{l}\text { Measures of Underlying approach Who is surveyed measured } \\
\text { reputation }\end{array}$ \\
\hline
\end{tabular}

$\begin{array}{ccc}\begin{array}{c}\text { MAC list } \\ \text { Fortune }\end{array} & \begin{array}{c}\text { Reputation described in terms } \\ \text { of characteristics that are } \\ \text { Magazine) }\end{array} & \begin{array}{c}\text { CEOs and } \\ \text { financial analysts }\end{array} \\ & \text { CEO and journalists }\end{array}$

\section{Reputation} quotient (RQ)

(Fombrun, 1996)

\section{Reputation described in} terms of stakeholder expectations of organizations

\author{
Many stakeholder \\ groups of a business \\ including the general \\ public, customers, \\ employees, suppliers, \\ investors, etc
}

\section{Customers and employees}
Many stakeholder groups of a business including customers, employees, suppliers, investors, etc

Eight characteristics of reputation (innovation, financial soundness, employee talent, use of corporate assets, long-term investment value, social responsibility, quality of management, quality of products and services)

Statistical analysis suggest that all eight characteristics factor on one dimension

Six pillars of reputation (emotional appeal, products and services, vision and leadership, workplace environment, financial performance, social responsibility) Statistical analysis suggests that the six pillars group into two dimensions of reputation: emotional appeal as one dimension and the remaining pillars as second dimension

Seven dimensions of corporate personality (agreeableness, enterprise, competence, chic, ruthlessness, machismo, informality) Distinct dimensions are supported by statistical analysis

Three dimensions: experiences (including for example sub-dimensions such as communication, material benefits, experience of outside influences), feelings (including sub-dimensions trust and positive emotions) and intentions (including sub-dimensions of supportive behaviors such as advocacy and retention of stakeholders towards a business) Distinct dimensions and sub-dimensions are supported by statistical analysis methodology. While others, such as Davies et al. (2003) also incorporated customers and employees in the refinement of their scales, their conceptualization does not begin with stakeholder expectations, but rather with the application of a personality metaphor.

\section{CORPORATE RESPONSIBILITY}

Corporate Responsibility (CR) is a concept in business research with roots in Business and
Society literature (Andriof and Waddock, 2002). In this arena it is used as a broad term to describe the issues relating to the responsibilities of business. CR is closely linked to other concepts in the Business and Society literature, most importantly the concept of Corporate Social Responsibility (CSR) (eg Lockett et al., 2006; Windsor, 2006; Moir, 2001), but has been differentiated from CSR as being broader and encompassing 
day-to-day operating practices and strategies of business as well as impacts on society and the environment (Ahmad et al., 2003; Andriof and Waddock, 2002). The term CR drops the word social from previous conceptualizations 'to signal an emerging sense that responsibilities are fundamental to all actions, decisions, behaviours and impacts of business' (Waddock, 2003: 15). CSR, on the other hand, can thus usefully be seen as relating to the specific social, philanthropic and community focussed responsibilities of business.

CR rather than any of its related concepts is investigated in this paper for two reasons: First, there is a growing use and acceptance within both the practitioner (eg Eco Conference, 2006; EABIS Conference, 2006; Zadek, 2004) and academic (eg Andriof and Waddock, 2002; Waddock, 2003) communities for the term CR. Second, CR being a broad concept, allows for the investigation of both the social and other aspects of responsibility within the same study (MacMillan et al. 2004; Waddock, 2003). A discussion about the link between reputation and the different aspects of responsibility should therefore ensue.

Despite this distinction, a fundamental problem in Business and Society literature is that there is no universally agreed definition of CR or CSR (Windsor, 2006; Garriga and Mele, 2004; Waddock, 2003). The lack of agreement in terms and definitions has not stopped academics and practitioners from conceptualizing and measuring $\mathrm{CR}$ and its related constructs in many different ways.

Academic examples include categorizing corporate social performance in terms of people and products (Johnson and Greening, 1999) and in terms of social issues, such as employee relations, diversity issues, product issues, community relations and environmental issues (Hillman and Keim, 2001). Practitioner examples include the triple bottom line of financial, social and environmental performance (Elkington, 1997) and the Global Reporting Initiative (GRI) that includes reports on employees, customers, community, supply chain and business partners among other aspects. While these conceptualizations often survey stakeholder opinion, few actually involve stakeholders in a rigorous and systematic way from the definition of the concept through to measurement. This leaves an opportunity for stakeholders to be involved in defining responsibility and identifying issues that are relevant to them. It is clear from our review above that researchers in the Corporate Reputation domain have already developed conceptualizations and models of Corporate Reputation by engaging stakeholders in concept development and through the mapping of their perceptions (eg MacMillan et al., 2004; Fombrun, 1996). It is also now clear that researchers in the area of Business and Society have yet to carry out similar conceptual development for $\mathrm{CR}$ and its related constructs (Windsor, 2006; Neville et al., 2005). Before we can understand how responsibility and reputation interact, it follows that we first have to have conceptualizations of both concepts that are derived from a similar approach. This will allow us to compare and contrast the concepts more easily and rigorously.

A number of scholars have thus called for a conceptualization of CR to be developed from a stakeholder perspective (Wood et al., 2006; Waddock, 2002). Taking account of how stakeholders make sense of CR would also add to the legitimacy of any models and measures developed. This is because the opinions of key groups such as customers, employees or suppliers would be acknowledged in an explicit way (Wood et al., 2006). For these reasons, this paper sets out to develop a conceptualization of CR that is built through an engagement with stakeholders from the inception stage. Before this is done, the next section reviews key elements of stakeholder theory relevant to this approach. 


\section{STAKEHOLDER THEORY}

Stakeholder theory is developed from strategic management literature (Freeman, 1984). Its core theme is that businesses have obligations to a broader group of stakeholders than just shareholders. Freeman (1984) defines stakeholders as ' $(. .$.$) any group or individu-$ al who can affect or is affected by the achievement of the organization's objective'. Stakeholder theory has developed to view the firm as a nexus of relationships (Jones, 1995). This approach suggests that mutual trust between organizations and stakeholders are key drivers of long-term sustainable success (Jones, 1995).

Stakeholder theory also moved forward significantly with the contribution of Donaldson and Preston (1995). They suggest that work conducted with stakeholders could be viewed as descriptive, instrumental and normative. Put simply, descriptive approaches seek to investigate and describe 'how' organizations and stakeholders relate to each other. Instrumental approaches investigate 'what happens if' organizations relate to stakeholders in certain ways. Normative approaches suggest how a firm 'should' relate to its stakeholders. When applied to a research setting, it seems reasonable that the Donaldson and Preston taxonomy could in some ways be viewed as sequential. This is because it follows that concepts first need to be described before their instrumental or normative value can be established.

Another key tenant of stakeholder theory is that concepts, such as responsibility, are multifaceted and possess multiple criteria that can change over time (Harrison and Freeman, 1999). This is because concepts should reflect the different views and needs of stakeholders (Mitchell et al., 1997). It is thus suggested that criteria should be established and measured in a process of consultation and engagement between organizations and stakeholders (Wood et al., 2006; Jones, 1995). This is supported by Neville et al. (2005), who state that the extent of an organization's responsibilities is framed within the context of an organization's relationship with its stakeholders.

Much of the research examining stakeholders in the business and society literature is concerned with instrumental issues and normative issues. In the realm of descriptive research, little empirical work has looked into what stakeholders think responsibility is. This is, however, particularly important if we are to accept the thesis of both Connolly et al. (1980) and Jones (1995), who suggest that instrumental and normative research should be built upon the foundation of strong descriptive research. This paper aims to provide such a foundation.

\section{The Need for a Conceptualization of CR from a Stakeholder Perspective}

The conceptualizations of reputation developed by MacMillan et al. (2004) and Fombrun (1996) reviewed in the reputation literature involved stakeholders in their development. They drew upon the key tenants of stakeholder theory outlined above. As was outlined in the previous section, current conceptualizations of responsibility have been produced without systematically and rigorously engaging stakeholders in their development. Furthermore, current measures often focus primarily on the social activities of a business such as charitable donations, community involvement and employee volunteerism (Maignan and Ferrell, 2004).

It is not clear however, whether these issues are similar or different to stakeholder conceptualizations of the social elements of responsibility, let alone what the views of stakeholders would be regarding a wider notion of responsibility (Dawkins and Lewis, 2003). As a result, the indicators currently used by companies to demonstrate $\mathrm{CR}$ are often said to be pragmatic or public relations-based responses to pressure from non-governmental organizations (NGOs) (Esrock and Leichty, 1998; Sumner, 2004) and are seen to lack credibility with 
stakeholders (Barone et al., 2000; Mohr et al., 2001). There is, however, a consensus among practitioners and academics alike that it is important to understand and address stakeholder expectations of CR (Wood et al., 2006; MacMillan et al., 2004; Waddock, 2002). It is our aim to import the approaches and rigor around which reputation measures were developed to the field of CR. In particular to apply similar techniques used by Fombrun and Van Riel (2004) and MacMillan et al. (2004).

This paper continues by describing a research project that sets out to define responsibility from the perspective of stakeholders and fills this gap. Customers and employees of a financial institution are the participants and sources of data in this study. As such the study provides a first step to conceptualize responsibility from a stakeholder perspective. A formal comparison with the reputation models, as outlined in the introduction, is then given.

\section{METHODOLOGY AND RESEARCH DESIGN}

The research was conducted with a financial service company in the UK and was part of a larger project investigating responsibility and its impact in the financial service sector. Data gathering for the research reported in this paper included 15 in-depth interviews with employees of three different branches. Furthermore, data gathering included four focus groups with 8-12 customers each in three different areas of the UK. The views of a total of 56 customers and employees were used as data in the qualitative analysis. The design of the interviews was informed by Kvale (1996). The design of the customer focus groups was informed by Marshall and Rossman (1995).

The study was based upon an inductive research design. Following key qualitative research techniques, the discovery of employee and customer construction of reality as a basis for conceptual understanding builds on elements of grounded theory (Glaser and
Strauss, 1967; Easterby-Smith et al., 2002). In a similar way to Fombrun (1996), who asked general questions such as 'What is Corporate Reputation' and 'What does it entail', the current research study also used general questions, such as 'What is Corporate Responsibility' and 'What does it entail'. While Fombrun asked stakeholders to think of business in general and good and bad companies, this research study is carried out in the context of a relationship between stakeholders and a target business. This is done to take account of stakeholder theorists and social psychologists who suggest that issues are more richly understood when they are embedded into experience.

It should be noted that the aim of the research is to investigate mental conceptualizations of CR among customers and employees. Therefore, the design did not employ existing conceptualizations of CR, or aspects thereof, as practical research guidelines. In the same way, no organizational value propositions such as mission and vision statements of the participating research organization were employed as guidelines.

\section{DATA ANALYSIS AND RESULTS}

The field notes and transcripts were analyzed in an inductive way based on Miles and Huberman (1994) who suggest a systematic process for making sense of and displaying data, including the following stages that are now outlined:

1. Preparation of written-up field notes.

2. Qualitative clustering to identify trends in the data.

3. Further analysis to identify high-level themes and links between clusters.

\section{Field Notes}

The focus groups with customers were audio- and videotaped and subsequently transcribed. Interviews with employees could not be taped due to reasons of 
confidentiality. Therefore, a second researcher who took notes during the interviews accompanied the facilitator.

\section{Qualitative Clustering to Identify Trends in the Data}

The written up field-notes and transcripts were then analyzed by identifying dominant trends that were repeatedly mentioned by customers and employees. The method of identifying trends was based on a qualitative clustering technique described by Miles and Huberman (1994). Qualitative clustering helps to understand data by grouping and then conceptualizing units that have similar patterns or characteristics. Based on this technique, eight distinct clusters of responsibility were identified from the data that represent customer and employee thoughts on what a business is responsible for. These eight clusters are responsibility for: (1) communication with them, (2) the kind of benefits a business offers them, (3) behaving with integrity, transparency and accountability towards them, (4) how a business makes them feel, (5) how a business relates to local communities, (6) how a business relates to the wider society, including the environ- ment, (7) how business behaves towards other exchange stakeholders and (8) being a financially stable and successful business in the long term.

\section{HIGH-LEVEL THEMES AND LINKS BET- WEEN CLUSTERS OF RESPONSIBILITY}

These eight clusters were then categorized in three high-level themes that reflect who these responsibilities are addressed to in the minds of stakeholders. So, in the minds of stakeholders a business is responsible for how it relates to (1) 'me', (2) 'others' and (3) 'itself'. These three themes with corresponding clusters are shown in Table 2.

Table 3 gives some specific examples of how these themes and clusters are expressed in the customer and employee data from the financial service organization studied.

It should be noted that there is a high degree of overlap between the themes and the clusters that underpin customer and employee understanding of CR. Expression of these clusters seems to be more similar when referring to issues removed from their own relationship, such as how business relates to others and to itself. While this is the case,

Table 2: Themes and Clusters of Responsibility from a Stakeholder Perspective

Three themes of responsibility

A business is responsible for...

...how it relates

to $M E$

...how it relates to OTHERS

(that includes stakeholders and society in large)
Eight clusters of responsibility

through communication

through the kind of benefits it offers to me

through the way it behaves with integrity, transparency

and accountability

and how that makes me feel

The local community

The wider society

Towards other direct exchange stakeholders (ie employees, customers, suppliers and shareholders) 


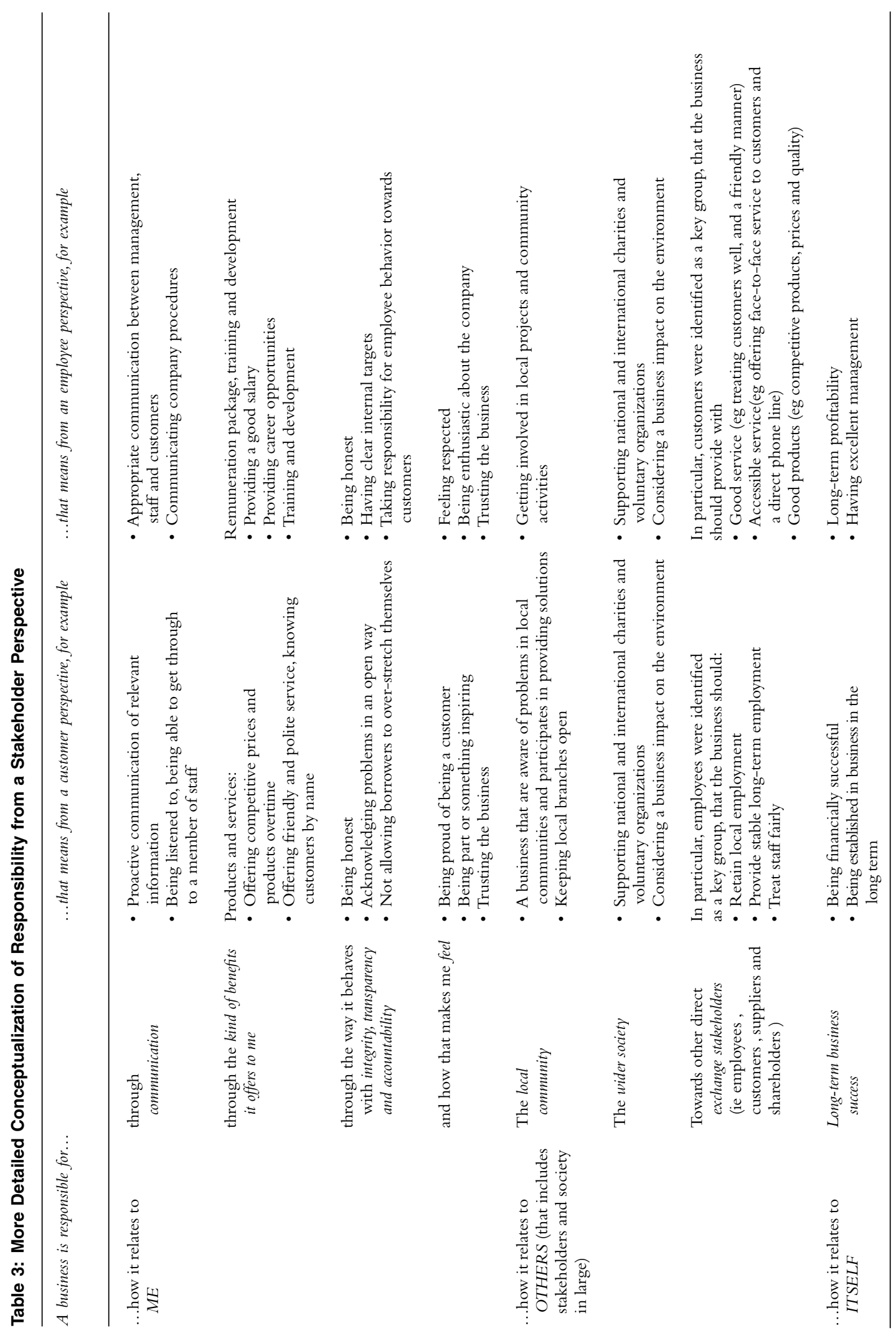


the specific expression of concepts is often different, particularly when relating to how a business relates to them as a focal stakeholder group.

\section{DISCUSSION OF THE RESULTS}

The most noticeable finding from the research is how comprehensive and extensive customers' and employees' conceptualization of CR is. The analysis reveals a wide spread of business behaviors and characteristics associated with the notion of CR such as the way a business behaves towards people in its daily activities, the way a business makes people feel, aspects of profitability and communication. This is particularly interesting when one considers how the term CR is sometimes used in a very narrow sense to represent charitable donations, community involvement and employee voluntarism, which are all extra-curricular activities and not core aspects of how a business makes its profits. While customers and employees see support of good causes and the environment as part of the picture, it does not seem to be their main priority. The results do suggest however, that $\mathrm{CR}$ is a concept that embraces both the social aspects normally associated with CSR and wider elements associated with more mainstream business practice.

The results also suggest that customers and employees see CR as being reflected in similar issues. This has implications for the management of multiple stakeholder relationships in that it suggests that organizations can manage and demonstrate their responsibility using a similar set of issues. Theorists such as (Carmeli, 2005; Dutton et al., 1994; Smidts et al., 2001) could build on this in their work linking internal and external reputations.

The most important business responsibilities in customer and employee understanding are core aspects of business behavior and strategy such as the way a busi- ness runs its operations and treats customers and staff and whether it is profitable or not. Indeed of the eight clusters identified, only two (How a business relates to the local community and How it relates to wider society) did not relate to the core activities of business. The other six clusters refer to how a business relates to stakeholders in terms of their daily business activities and whether or not a business makes money.

The message to businesses here is clear. If they want to be seen as responsible by customers and employees, they need to get the relationship right with these groups as well as meeting wider social obligations. The findings should also come as a relief to managers who often wrestle with the 'conflict' between being responsible and providing good service and profitability. The message is again clear: businesses that deliver value and service to customers and are honest and fair to employees should be perceived as being responsible. If we believe past research, these activities should also bring profit (eg MacMillan et al., 2004).

\section{LINKING CR AND CORPORATE REPUTATION}

A comparison of the conceptualization of responsibility provided by the data analyzed in this paper and current measures and models of reputation provides the framework for a discussion about links between responsibility and reputation. As a starting point, similarities between elements of CR, as represented by the findings of the current study, and elements of Corporate Reputation, as represented by the SPIRIT-Model of Reputation (MacMillan et al., 2004) and the RQ Model (Fombrun and Van Riel, 2004) are summarized in Table 4.

For ease of reference similarities and differences are now discussed in terms of the three themes of CR developed from the empirical research in this paper. 
Table 4: Comparison between Findings of the Current Study and Reputation Models

Themes and clusters of responsibilities
(Results of the current study)
$\begin{aligned} & \text { Three themes of } \\ & \text { responsibility }\end{aligned}$

A business is responsible for:

\begin{tabular}{|l|l} 
Reputation models & \\
\hline SPIRIT &
\end{tabular}

MacMillan et al. (2004)Data from one or more stakeholder groups on their perceptions of a business
$\mathbf{R Q}$

Fombrun and Van Riel (2004)

Data from one or more stakeholder groups on their perceptions of a business

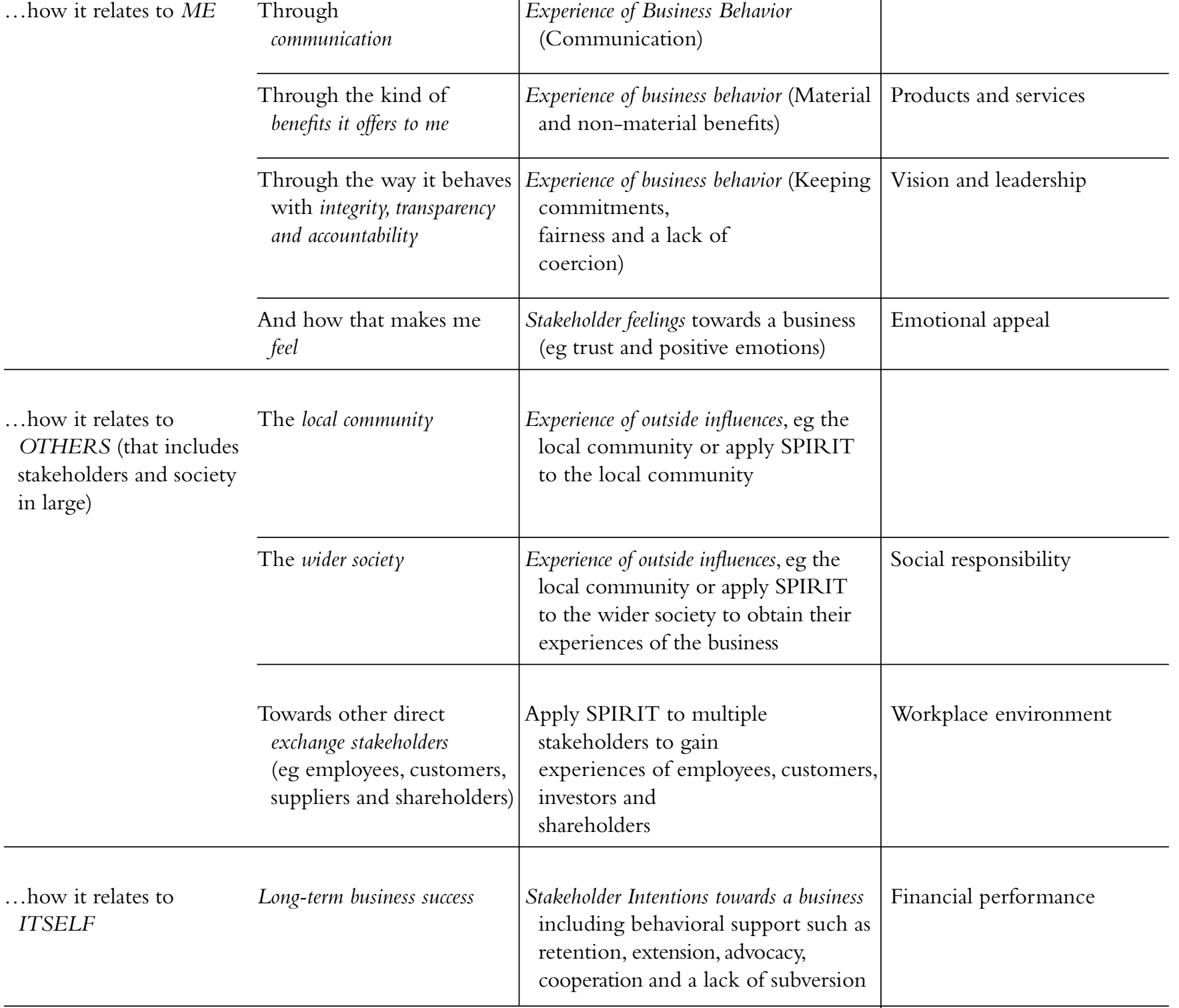


Theme 1: Stakeholder Expectation about 'How a Business Relates to Me'

It seems that the theme of 'how an organization relates to me as a stakeholder' is particularly similar to the part of SPIRIT that measures 'stakeholder experiences of an organization'. Both the above-mentioned themes in the CR and SPIRIT models, for example, include a measure of how an organization communicates with stakeholders, the benefits stakeholders receive from organizations, the integrity with which stakeholders are treated and how stakeholders feel towards the business.

The RQ also seems to overlap with the CR model in terms of this theme of how an organization relates to me as a stakeholder'. In particular, the pillar of 'products and services' seem to relate very strongly to 'benefits offered to me (as a customer)' and the pillar of 'emotional appeal' seem to link very strongly to 'how an organization makes me feel'. The other two clusters of this theme of responsibility, in terms of the communication and integrity seem to be less closely linked to the RQ. However, it could be argued that elements of vision and leadership should correlate with notions of integrity.

\section{Theme 2: Stakeholder Expectations about 'How a Business Relates to Others'} In terms of the second theme of responsibility, 'how an organization is seen to relate to others', the themes and dimensions from reputation models fit well, but not with the same degree of synergy as the previous theme of CR. This is because reputation research often provides data from the perspective of one stakeholder group only in terms of how the organization relates to them. RQ and SPIRIT surveys are, for example, often conducted with customers or employees of an organization, while it is less common for surveys to be conducted simultaneously with both these groups, let alone multiple stake- holders. Ideally, data regarding this dimension of responsibility should be obtained by conducting research directly with different stakeholder groups regarding their individual relationships with the organization.

Research with one stakeholder group does, however, offer an opportunity to gather information that is relevant to this theme of responsibility because reputation models often require stakeholders to give their opinion about how organizations relate to stakeholder groups other than their own. An RQ with customers of an organization, for example, will provide an indication of how customers perceive an organization to be performing in terms of 'social responsibility'. This could, for example, relate to the dimension of responsibility relating to how an organization is seen to impact the wider society'. An RQ with customers would also, for example, provide an indication of how customers perceive the 'workplace environment' of an organization. This may provide some indication of the dimension of responsibility that relates to 'how an organization relates to its employees'.

When SPIRIT is applied to one stakeholder group, it provides much more information about the details of the focal relationship than the RQ, but less information about how this focal group perceive an organization to relate to others. It does, however, provides an indication of how other groups may influence the reputation of an organization in the minds of one focal stakeholder group. This could include, for example, customer perceptions of how an organization relates to the local community and wider society and an indication of how these perceptions influence the reputation of the organization in their minds. It does not, however, overtly ask stakeholders how other groups are treated by the organization.

This example highlights the differences between the SPIRIT model and the RQ and also highlights the importance of carrying out further multi-stakeholder 
research in both the reputation and responsibility fields. It seems clear that organizations will obtain a more accurate picture of their reputation and whether they are meeting their responsibilities, if they survey different stakeholder groups directly and simultaneously.

If simultaneously applied to various stakeholders, the SPIRIT model seems to provide the closest link to the responsibility model. This is because it asks stakeholders directly about issues that relate to their own relationship and that they have direct experience of. The RQ, on the other hand, may require a focal stakeholder group to make judgments about things that are beyond their experience and knowledge. A customer RQ, would, for example, ask customers about their perceptions of an organization's 'workplace environment', while an employee RQ may ask about an organization's 'products and services' and 'financial performance'. Issues that each group may not necessarily know that much about and that more closely links to the experience of another stakeholder group. Doing an RQ with multiple stakeholders, may therefore, provide more of an overview of the reputation of an organization in terms of macro issues, rather than an analysis of how an organizations relates to each stakeholder group in term of issues that are important to them.

The discussion above highlights the most crucial differences between the RQ and SPIRIT and suggests that organizations have important decisions to make when choosing reputation and responsibility models. The RQ may for example, provide a more holistic picture of responsibility when applied to just one group, while SPIRIT fits well with a multi-stakeholder approach. It also indicates that SPIRIT and the RQ could be modified to take account of the needs of responsibility practitioners. Choices of research approach will have to be balanced in terms of organizational need, costs and time constraints.

\section{Theme 3: Stakeholder Expectations} about 'How a Business Relates to Itself'

In terms of the final dimension of responsibility, 'how an organization relates to itself in terms of long-term business success', both reputation models provide strong indicators. The SPIRIT model provides an indication of stakeholder intentions to be supportive of an organization in the future. Since this relates to issues such as customers continuing to buy products and employees being committed to their work, it provides an indication of the future financial success and sustainability of an organization. Therefore, it provides a strong indication of the future sustainability of an organization. The RQ, on the other hand, provides an indication of the perception of the past financial performance of an organization. While not providing an indication of future performance, this is a key element of past performance that will determine whether an organization is seen to be responsible at any particular moment in time. Both measures seem complimentary.

\section{SUMMARY OF THE COMPARISON BETWEEN THE CR MODEL AND REPUTATION MODELS}

In summary, an analysis of Table 4 suggests that stakeholder understanding of $\mathrm{CR}$ is, in important aspects, similar to stakeholder understanding of Corporate Reputation, as expressed by the two reputation models analyzed. This poses serious questions for theorists who suggest that CR is a key antecedent of Corporate Reputation or even suggest that $\mathrm{CR}$ and Corporate Reputation are distinct concepts. Rather, the results suggest that far from being distinct the two concepts are largely overlapping. In other words, when taking a stakeholder perspective, Corporate Reputation and CR are both expressed through similar and overlapping corporate behaviors and understood in terms of similar and overlapping stakeholder perceptions. In this way rather than viewing reputation and responsibility as two separate 
concepts, they may more usefully be thought of as two sides of the same coin.

This has a number of implications, but critically it may mean that reputation models could be used to provide a starting point for the provision of proxy-measures of responsibility. In addition, the conceptualization of responsibility provided in this paper suggests that organizations can use measures provided by reputation models to communicate and report on the responsibility of their businesses in terms of issues that are relevant to stakeholders. In this way data could be collected for a number of purposes. Also, these measures could be incorporated into strategic decision-making that is aimed at growing the value of the business as well as ensuring responsible behavior. It might also provide an opportunity for reputation and responsibility practitioners and academics to join forces and move both concepts forward.

Another interesting finding is that despite differences in the interpretation of aspects of the clusters, on a conceptual level, employees and customers construct CR in a very similar way. From a theoretical point it suggests that a generic conceptualization of CR and Corporate Reputation could be developed that is applicable to different stakeholder groups. This could then be operationalized in different ways with different organizations and stakeholders as our research suggests different stakeholders express the same underlying themes in different ways. From a practical point it suggests that a business can simultaneously enhance its reputation and demonstrate its responsibility by meeting stakeholder expectations. However, the expression of specific relationship issues still highlights importance of understanding the specifics in the expectations of different stakeholder groups before operationalizing responsibility or reputation in organizations.

\section{LIMITATIONS AND FUTURE RESEARCH}

The research focuses on the concepts of CR and Corporate Reputation. The results should not be taken to be generalizable to other concepts such as CSR. While the results suggest that social elements are key components of $\mathrm{CR}$, richer and more in-depth views of CSR may be obtained by taking a similar inductive approach and researching this concept in more detail. Researchers are thus encouraged to conduct this type of research with different type of corporate entity and concepts that embrace different elements of those identified in this study or in the literature.

The current study has been conducted with customers and employees of a financial service company in the UK and it is not clear in how far the findings can be generalized to other industries, stakeholders or countries. Future research could extend exploratory research into stakeholder expectations of CR including other stakeholder groups such as suppliers, investors, communities and NGOs. It would also be interesting to conduct similar research with different businesses and in different industries and countries to compare how far expectations of $\mathrm{CR}$ can be compared and separated into specific business responsibilities, specific industry responsibilities, cultural responsibilities and general responsibilities. Since a key tenant of stakeholder theory is that conceptualizations are multifaceted and dependent upon different stakeholder needs, the overlap between reputation models and conceptualizations of CR could be further investigated in different situations.

\section{CONCLUSION}

\section{Implications for Academics}

The study has a number of implications for the academic world. First, the findings of this study suggest that customers and employees conceptualize CR in three ways: as business behavior towards them, as business behavior towards other stakeholder groups and as business behavior that ensures a business' 
own success. When broken down into its constituent parts these relate to, for example, issues such as how an organization provides benefits to stakeholders through its products and services, how it communicates with stakeholders as well as the emotional impact that an organization has on stakeholders. Second, in a comparison of these findings with prominent reputation models it was found that there is a great overlap between elements of reputation models and aspects of CR. This was particularly the case in that both investigate how a business relates to its various stakeholders in terms of key business activities. Measuring CR may therefore, not be that different from measuring Corporate Reputation, as both can be rooted in stakeholder relationships. Third, this paper provides the opportunity to apply the advances in the conceptual development of reputation to the field of CR.

\section{Implications for the Practitioner}

The study also has a number of implications for practitioners. One implication is the way Corporate Reputation and CR are managed in organization. Since the findings suggest that the areas of reputation and responsibility are overlapping, it follows that the concepts could be managed in an integrated way. Perhaps organizations already have the measures and processes they need to manage both concepts in separate business units. For this reason, organizations are encouraged to explore how Corporate Reputation and CR activities could positively impact each other. A further implication is that involving stakeholders in defining an organization's responsibilities can add to the legitimacy of how the concept of responsibility can be defined, implemented and measured. Finally, it is clear that elements of CR have been closely linked to Corporate Reputation. This should give practitioners the ammunition they need to justify the costs that are sometimes associated with the field.

\section{CONCLUDING REMARKS}

Overall, the major conclusion is that practitioners and researchers in Corporate Reputation and CR are encouraged to explore how they could work together to raise the profile of both fields, conduct further research and influence strategic decision making.

\section{References}

Ahmad, S.J., O’Regan, N. and Ghobadian, A. (2003) 'Managing for performance: Corporate responsibility and internal stakeholders', International Journal of Business Performance Management, 5(2/3), 141-153.

Andriof, J. and Waddock, S. (2002) 'Unfolding stakeholder engagement', in S. Sutherland Rahman, S. Waddock, J. Andriof and B. Husted (eds.), Chapter One, Unfolding Stakeholder Thinking, Greenleaf, UK.

Barone, M.J., Mjyazaki, A.D. and Taylor, K. A. et al. (2000) 'The influence of cause-related marketing on consumer choice: Does one good turn deserve another', Journal of the Academy of Marketing Science, 28(2), 248-262.

Brammer, S. and Millington, A. (2005) 'Corporate reputation and philanthropy: An empirical analysis', Journal of Business Ethics, 61(1), 29-44.

Brammer, S. and Pavelin, S. (2006) 'Corporate reputation and social performance: The importance of fit', Journal of Management Studies, 43(3), 435-455.

Carmeli, A. (2005) 'Perceived external prestige, affective commitment, and citizenship behaviors', Organization Studies, 26(3), 443-464.

Connolly, T., Conlon, E.J. and Deutsch, S.J. (1980) 'Organizational effectiveness: A multiple-constituency approach', Academy of Management Review, 5(2), 211-217.

Davies, G., Chun, R., Da Silva, R.V. and Roper, S. (2003) Corporate Reputation and Competitiveness, Routledge, London and New York.

Dawkins, J. and Lewis, S. (2003) 'CSR in stakeholder expectations: And their implication for company strategy', Journal of Business Ethics, 44(2/3), 185-193.

Donaldson, T. and Preston, L.E. (1995) 'The stakeholder theory of the corporation: Concepts, evidence, and implications', Academy of Management Review, 20(1), 65-91.

Dutton, J.E., Dukerich, J.M. and Harquail, C.V. (1994) 'Organizational images and member identification', Administrative Science Quarterly, 39, 239-263.

EABIS Conference (2006) Conference held in September 2006 in Milan, organized by the European Academy of Business in Society. 
Easterby-Smith, M., Thorpe, R. and Lowe, A. et al. (2002) Management Research, Sage Publication, London.

ECO Conference (2006). ( http://06.economie.co.uk.). Elkington, J. (1997) Cannibals with Forks, Capstone Publishing Limited, Oxford, UK.

Esrock, S.L. and Leichty, G.B. (1998) 'Social responsibility and corporate web pages: Self-presentation or agenda setting', Public Relations Review, 24(3), 305-317.

Fombrun, C.J. (1996) Reputation: Realizing Value from the Corporate Image, Harvard Business School Press, Boston.

Fombrun, C.J. (2005) 'Building corporate reputation through CSR initiatives: Evolving standards', Corporate Reputation Review, 8(1), 7-11.

Fombrun, C.J. and Van Riel, C.B.M. (2004) Fame and Fortune: How Successful Companies Build Winning Reputations, Prentice-Hall, Upper Saddle River, NJ.

Freeman (1984) Strategic Management: A Stakeholder Approach, Prentice-Hall, Englewood Cliffs, NJ.

Fryxell, G.E. and Wang, J. (1994) 'The fortune corporate 'reputation' index. Reputation for what?' Journal of Management, 20(1), 1-14.

Garriga, E. and Mele, D. (2004) 'Corporate social responsibility theories: Mapping the territory', Journal of Business Ethics, 53(1/2), 51-71.

Glaser, B.G. and Strauss, A.L. (1967) The Discovery of Grounded Theory: Strategies for Qualitative Research, Aldine Publishing Company, Chicago.

Harrison, J.S. and Freeman, R.E. (1999) 'Stakeholders, social responsibility, and performance: Empirical evidence and theoretical perspectives', Academy of Management Journal, 42(5), 479-485.

Hillman, A.J. and Keim, G.D. (2001) 'Shareholder value, stakeholder management, and social issues: What's the bottom line?' Strategic Management Journal, 22(2), 125-139.

Johnson, R.A. and Greening, D.W. (1999) 'The effects of corporate governance and institutional ownership types on corporate social performance', Academy of Management Journal, 42(5), 564-576.

Jones, T. (1995) 'Instrumental stakeholder theory: A synthesis of ethics and economics', Academy of Management Review, 20(2), 404-437.

Kvale, S. (1996) Interviews: An Introduction to Qualitative Research Interviewing, Sage Publication, Thousands Oaks.

Lindgreen, A. and Swaen, V. (2005) 'Corporate citizenship: Let not relationship marketing escape the management toolbox', Corporate Reputation Review, 7(4), 346-363.

Lockett, A., Moon, J. and Visser, W. (2006) 'Corporate social responsibility in management research: Focus, nature, salience and sources of influence', Journal of Management Studies, 43(1), 115-136.
MacMillan, K., Money, K., Downing, S. and Hillenbrand, C. (2004) 'Giving your organisation SPIRIT: An overview and call to action for directors on issues of corporate governance, corporate reputation and corporate responsibility', Journal of General Management, 30(2), 15-42.

Mahon, J. (2002) 'Corporate reputation: A research agenda using strategy and stakeholder literature', Business and Society, 41(4), 415-445.

Maignan, I. and Ferrell, O.C. (2004) 'Corporate social responsibility and marketing: An integrative framework', Journal of the Academy of Marketing Science, 32(1), 3-19.

Marshall, C. and Rossman, G.B. (1995) Designing Qualitative Research, Sage Publications, London.

Miles, M.B. and Huberman, M.A. (1994) Qualitative Data Analysis, Sage Publication, Thousand Oaks, CA.

Mitchell, R.K., Agle, B.R and Wood, D.J. (1997) 'Toward a theory of stakeholder identification and salience: Defining the principle of who and what really counts', Academy of Management Review, 22(4), 853-886.

Mohr, L.A., Webb, D.J. and Harris, K.E. et al. (2001) 'Do consumers expect companies to be socially responsible? The impact of corporate social responsibility on buying behavior', The Journal of Consumer Affairs, 35(1), 45-72.

Moir, L. (2001) 'What do we mean by corporate social responsibility', Corporate Governance, 1(2), 16-23.

Neville, B.A., Bell, S.J. and Menguec, B. (2005) 'Corporate reputation, stakeholders and the social performance-financial performance relationship', European Journal of Marketing, 39(9/10), 1184-1220.

Schnietz, K.E. and Epstein, M.J. (2005) 'Exploring the financial value of a reputation for corporate social responsibility during a crisis', Corporate Reputation Review, 7(4), 327-345.

Smidts, A., Pruyn, T.H. and Van Riel, C.B.M. (2001) 'The impact of employee communication and perceived external prestige on organizational identification', Academy of Management Journal, 44(5), 1051-1062.

Sumner, J. (2004) 'Taking the scepticism out of responsibility reporting', Corporate Responsibility Management, 1(2), 2-3.

Tucker, L. and Melewar, T.C. (2005) 'Corporate reputation and crisis management: The threat and manageability of anti-corporatism', Corporate Reputation Review, 7(4), 377-387.

Waddock, S. (2002) Leading Corporate Citizens. Vision, Values, Value Added, McGraw-Hill, Boston.

Waddock, S. (2003) 'Stakeholder performance implications of corporate responsibility', International Journal of Performance Management, 5(2/3), 114-124. 
Windsor, D. (2006) 'Corporate social responsibility: Three key approaches', Journal of Management Studies, 43(1), 93-114.

Wood, D.J., Logsdon, J.M., Lewellyn, P.G. and Davenport, K. (2006) Global Business Citizenship. A Trans- formative Framework for Ethics and Sustainable Capitalism, M.E. Sharpe Inc., Armonk, NY.

Zadek, S. (2004) 'The path to corporate responsibility', Harvard Business Review. December 2004, 82(12), 125-132. 